\title{
Chemical Composition of European Propolis: Expected and Unexpected Results
}

Vassya Bankova ${ }^{\mathrm{a}, *}$, Milena Popova ${ }^{\mathrm{a}}$, Stefan Bogdanov ${ }^{\mathrm{b}}$ and Anna-Gloria Sabatini ${ }^{\mathrm{c}}$

${ }^{a}$ Institute of Organic Chemistry with Centre of Phytochemistry, Bulgarian Academy of Sciences, 1113 Sofia, Bulgaria. E-mail: bankova@orgchm.bas.bg

b Swiss Bee Research Centre, FAM, Liebefeld, 3003 Bern, Switzerland

c National Institute of Beekeeping, 80 Via di Saliceto, Bologna, Italy

* Author for correspondence and reprint requests

Z. Naturforsch. 57c, 530-533 (2002); received February 18, 2002

Propolis, Phenolics, Phenolic Glycerides, Diterpenes

Ten propolis samples from Bulgaria, Italy and Switzerland were analyzed by GC-MS. As expected, most samples displayed the typical chemical pattern of "poplar" propolis: they contained pinocembrin, pinobanksin and its 3-O-acetate, chrysin, galangin, prenyl esters of caffeic and ferulic acids. Two samples differed significantly: one from the Graubünden Alpine region, Switzerland, rich in phenolic glycerides, and one from Sicily which contained only a limited number of phenolics and was rich in diterpenic acids.

\section{Introduction}

Propolis (bee glue) is a sticky dark-colored material that honeybees collect from living plants, mix it with wax and use it in the construction and adaptation of their nests, mainly to fill out cracks in the bee hive. It has been used in folk medicine since ancient times and is now known to be a natural medicine with antibacterial, antifungal, antitumoral, antioxidative, imunomodulatory and other beneficial activities (Burdock, 1998). The bud exudates of poplar trees (Populus spp., section Aigeiros) are the main source of European and North American bee glue (Bankova et al., 2000), chemical data showing a clear preference to $P$. nigra in Europe (Bankova and Kuleva, 1989; Greenaway et al., 1990; Garcia-Viguera et al., 1992; Hegazi et al., 2000). Whereas bud exudates of different poplar species and clones are frequently similar in qualitative composition, they may differ in their quantitative composition. These differences are reflected in the composition of propolis into which the bud exudate is incorporated (Greenaway et al., 1990).

The differences of propolis composition make it difficult to determine its quality as the available chemical methods for propolis quality control are unsatisfactory (Bankova and Marucci, 2000). That is why we started a project aimed at the development of procedures for standardization and quality control of propolis from Bulgaria, Italy and Swit- zerland. For that purpose we needed to find out the similarity between a number of samples with special accent on concentration of bioactive components: flavones, flavanones and total phenolics. First step was comparison of chemical composition of the samples by GC-MS analysis of their "balsam" (extract with $70 \%$ ethanol). In this article we report some unexpected results concerning chemical composition and plant origin of European propolis.

\section{Experimental}

\section{Propolis samples}

Geographic origin and time of collection are listed in Table I.

Table I. Site and time of collection of propolis samples.

\begin{tabular}{llc}
\hline Sample & Location & Year \\
\hline B-1 & Sredni Kolibi, Elena, Bulgaria & 2001 \\
B-2 & Enina, Kazanlak, Bulgaria & 2001 \\
B-3 & Konstantinovo, Burgas, Bulgaria & 2001 \\
I-1 & Piedmont, Italy & 2001 \\
I-2 & Emilia Romagna, Italy & 2001 \\
I-3 & Sicily, Italy & 2001 \\
S-1 & Bern, Switzerland, & 2000 \\
S-2 & Canton Bern, Switzerland & 1998 \\
S-3 & Canton Graubünden, Switzerland & 2000 \\
S-4 & Canton Ticino, Switzerland & 2000 \\
\hline
\end{tabular}




\section{Extraction and sample preparation}

Propolis, grated after cooling, was extracted for $24 \mathrm{~h}$ with $70 \%$ ethanol $(1: 10, \mathrm{w} / \mathrm{v})$ at room temperature. The extract was evaporated to dryness. About $5 \mathrm{mg}$ of the residue were mixed with $75 \mathrm{ml}$ of dry pyridine and $25 \mathrm{ml}$ bis(trimethylsilyl)trifluoracetamide (BSTFA), heated at $80^{\circ} \mathrm{C}$ for 20 min and analyzed by GC-MS.

\section{GC-MS analysis}

The GC-MS analysis was performed with a Hewlett Packard Gas Chromatograph 5890 Series II Plus linked to Hewlett Packard 5972 mass spectrometer system equipped with a $23 \mathrm{~m}$ long, $0.25 \mathrm{~mm}$ id, $0.5 \mathrm{~mm}$ film thickness HP5-MS capillary column. The temperature was programmed from $100^{\circ} \mathrm{C}$ to $310^{\circ} \mathrm{C}$ at a rate of $5^{\circ} \mathrm{C} \cdot \mathrm{min}^{-1}$. Helium was used as a carrier gas, flow rate $0.7 \mathrm{ml} \cdot \mathrm{min}^{-1}$. Split ratio $1: 80$, injector temperature $280{ }^{\circ} \mathrm{C}$, ionization voltage $70 \mathrm{eV}$.

\section{Identification of compounds}

The identification was accomplished using computer searches on a NIST98 MS data library. In some cases, when identical spectra have not been found, only the structural type of the corresponding component was proposed on the basis of its mass-spectral fragmentation. If available, reference compounds were co-chromatographed to confirm GC retention times. The components of ethanol extracts of propolis were determined by considering their areas as percentage of the total ion current. Some components remained uniden- tified because of the lack of authentic samples and library spectra of the corresponding compounds.

\section{Results and Discussion}

The chemical composition of three Bulgarian, three Italian and four Swiss samples was investigated by GC-MS after silylation. More than 80 individual compounds were identified. For this reason, the chemical composition is presented by means of the main type of compounds identified, not as percentage of individual substances The results obtained are presented in Table II.

As expected, most samples displayed the typical pattern of "poplar" propolis: they contained pinocembrin, pinobanksin and its 3-O-acetate, chrysin, galangin, prenyl esters of caffeic and ferulic acids, etc. The ratio between the main compound classes corresponded to that in P. nigra bud exudates. Two samples, however, differed significantly from the others.

In Table III the composition of "poplar propolis" is compared to the composition of the two propolis samples with unusual propolis composition (one of Swiss and one of Italian origin). One of the distinct samples originated from the canton Graubünden, Switzerland. The concentrations of the "poplar" phenolics were relatively low and some of the compounds typical for P. nigra (pinobanksin, prenyl caffeates) were completely absent. Instead, the concentrations of benzyl $p$-coumarate and benzyl ferulate were unusually high (over $5 \%)$. Also, unlike the samples originating from black poplar, this one contained significant

Table II. Chemical composition of ethanol extract of propolis samples (\% of total ion current $)^{\mathrm{a}}$.

\begin{tabular}{lrrrrrrrrrr}
\hline Compounds & B-1 & B-2 & B-3 & I-1 & I-2 & I-3 & S-1 & S-2 & S-3 & S-4 \\
\hline Aromatic compounds without & & & & & & & & & & \\
free phenolic group & 0.8 & \multicolumn{1}{c}{0.7} & 1.1 & 5.3 & 2.6 & 0.6 & 3.8 & 7.4 & 5.5 & 5.3 \\
Phenolics (other) & 0.4 & - & - & - & - & 0.2 & 1.1 & 1.3 & 0.2 & 2.3 \\
Phenolic acids & 7.7 & 2.2 & 3.5 & 4.5 & 3.2 & - & 12.7 & 11.5 & 11.9 & 17.5 \\
Phenolic acid esters & 5.7 & 12.1 & 10.3 & 13.9 & 17.0 & 0.2 & 4.8 & 12.1 & 21.9 & 16.6 \\
Flavanones and dihydroflavonols & 20.6 & 39.8 & 34.9 & 32.9 & 26.4 & 0.8 & 23.4 & 14.5 & 11.0 & 1.9 \\
Flavones and flavonols & 19.2 & 20.8 & 23.2 & 15.7 & 17.7 & 0.3 & 15.8 & 17.8 & 14.1 & 1.5 \\
Chalcones & 1.4 & 0.1 & 1.6 & 3.0 & 2.8 & - & 0.4 & 0.9 & 4.1 & 0.0 \\
Phenolic glycerides & 1.2 & - & - & - & - & - & 4.3 & 2.5 & 0.8 & 23.1 \\
\hline TOTAL PHENOLICS & 57.0 & 75.0 & 70.5 & 70.0 & 66.9 & 1.3 & 62.5 & 60.6 & 45.9 & 62.9 \\
\hline
\end{tabular}

a The ion current generated depends on the characteristics of the compound concerned and is not a true quantification. 
Table III. Main components of propolis of different plant origin ${ }^{\mathrm{a}}$.

\begin{tabular}{llcc}
\hline Component & $\begin{array}{l}\text { P. nigra propolis } \\
\text { Average } \\
\text { (min-max) }\end{array}$ & Swiss sample S-4 & Italian sample I-3 \\
\hline Pinocembrin & $7.2(4.2-12.4)$. & 0.3 & 0.2 \\
Pinobanksin & $3.7(1.7-6.2)$ & - & - \\
PinobanksinO-aceteate & $8.0(3.7-12.0)$ & - & 0.4 \\
Chrysin & $8.4(5.9-12.2)$ & 0.3 & 0.5 \\
Galangin & $7.8(6.6-10.3)$ & 0.2 & 0.2 \\
Pentenyl caffeates & $3.3(0.7-7.5)$ & - & 0.9 \\
Benzyl caffeate & $3.0(1.7-6.5)$ & 23.1 & - \\
Phenethyl caffeate & $2.8(1.4-5.3)$ & - & 53.2 \\
Phenolic glycerides & $1.1(0-3.7)$ & - &
\end{tabular}

amounts of phenolic glycerides: dicoumaroyl acetyl glycerol, diferuloyl acetyl glycerol, feruloyl coumaroyl acetyl glycerol, caffeoyl coumaroyl acetyl glycerol. These compounds have been isolated by Popravko et al. (1982) from North-Russian propolis and the exudate of $P$. tremula was found to be their plant source. This is the first time they are detected in propolis collected outside Russia. The Swiss propolis sample is gathered from a bee hive situated near the mountains at about $700 \mathrm{~m}$ altitude, with steep mountain slopes near by. In this area there are relatively high numbers of young $P$. tremula trees, and relatively few $P$. nigra. The same compounds were found in low concentrations (less than $4.3 \%$ ) in the other two Swiss samples and in one Bulgarian sample that came from a mountain region.

The second distinct sample originated from Sicily. It contained very low amounts of phenolic substances (less than 1.3\%). Instead, its main components were diterpenic acids, which remained unidentified because of the lack of authentic samples and library spectra of the corresponding com- pounds. It is an interesting finding, since such compounds were found in tropical propolis (Velikova et al., 2000; Banskota et al., 1998). This sample is obviously not of poplar origin, its plant source is not yet known. It will be the aim of future investigations to uncover this plant and study its biological action. This could be of interest because it has been shown that bees have the ability to find in their environment and use as propolis source the best agent to protect their hives against bacterial and fungal infections (Bankova et al., 1999).

These findings confirm that the determination of the "type" of propolis, according to its plant source, has to be the first step in quality control of bee glue (Bankova and Marcucci, 2000). This will allow to define the type of compounds that should be quantitated as main active propolis constituents. The present results demonstrate that even in Europe, where propolis is believed to be very well studied, there could be surprises concerning the plant origin and chemical composition of bee glue. 
Bankova V., De Castro S. L. and Marcucci M. C. (2000), Propolis: advances in chemistry and plant origin. Apidologie 31, 3-15.

Bankova V., Boudourova-Krasteva G., Sforcin J. M., Frete X., Kujumgiev A., Maimoni-Rodella R. and Popov S. (1999), Phytochemical evidence for the plant origin of Brazilian propolis from Sao Paulo state. Z. Naturforsch. 54c, 401-405.

Bankova V. and Kuleva L. (1989), Phenolic compounds in propolis from different regions in Bulgaria. Animal Sci. 2, 94-98 (in Bulgarian).

Bankova V. and Marcucci M. C. (2000), Standardization of propolis: Present status and perspectives. Bee World 81, 182-188.

Banskota A. H., Tezuka Y., Prasain J. K., Matsushige K. Saiki I. and Kadota Sh. (1998), Chemical constituents of Brazilian propolis and their cytotoxic activities, J. Nat. Prod. 61, 896-900.

Burdock G. A. (1998), Review of the biological properties and toxicity of bee propolis (propolis). Food Chem. Toxicol. 36, 347-363.
Garcia-Viguera C., Greenaway W. and Whatley F. R. (1992), Composition of propolis from two different Spanish regions. Z. Naturforsch. 47c, 634-637.

Greenaway W., Scaysbrook T. and Whatley F. R. (1990), The composition and plant origin of propolis: a report of work at Oxford. Bee World 71, 107-118.

Hegazi A. and Abd El Hady, F. K. (2000), Egyptian propolis: 1-Antimicrobial activity and chemical composition of Upper Egypt propolis. Z. Naturforsch. 56c, $82-88$.

Popravko S. A., Sokolov I. V. and Torgov I. V. (1982), New natural phenolic triglycerides. Chim. Prir. Soed. (2), 169-173.

Velikova M., Bankova V., Tsvetkova I., Kujumgiev A. and Marcucci M. C. (2000), Antibacterial ent-kaurene frim Brazilian propolis of native stingless bees. Fitoterapia 71, 693-696. 